\title{
The role of intellectual humility in foreign language enjoyment and foreign language classroom anxiety
}

\author{
Sharona Moskowitz a * (D), Jean-Marc Dewaele a \\ a Department of Applied Linguistics and Communication, Birkbeck, University of London, London, WC1H 5DT, UK
}

Received 22 April 2020 | Received in revised form 29 July 2020 | Accepted 31 August 2020

\author{
APA Citation: \\ Moskowitz, S., \& Dewaele, J.-M. (2020). The role of intellectual humility in foreign language enjoyment and foreign \\ language classroom anxiety. Eurasian Journal of Applied Linguistics, 6(3), 521-541. \\ Doi: $10.32601 /$ ejal.834664
}

\begin{abstract}
Intellectual humility (IH) involves a certain degree of selflessness and an accurate view of one's own worth and abilities. To date, IH has not been explicitly researched as a variable in the study of foreign language (FL) learning. The present mixed-methods study aims to explore possible links between FL learners' IH and their foreign language enjoyment (FLE) and foreign language classroom anxiety (FLCA). The survey was administered online entirely in Spanish and respondents were 163 adult Spanish L1 speakers enrolled in an EFL course at any level of proficiency. The research instrument was adapted from three established constructs: the CIHS (Comprehensive Intellectual Humility Scale) (Krumrei-Mancuso \& Rouse, 2016), the FLE Short Form (Botes, Dewaele \& Greiff, 2020) and the FLCA Short form scale (Dewaele \& MacIntyre, 2014). Feedback on three open-ended questions provided qualitative data. Results show that IH has a mixed and complex relationship with FLE and FLCA, with some IH domains negatively predicting FLE and both positively and negatively predicting FLCA. The current research is an attempt to widen the range of psychological factors that might affect FL classroom emotions.
\end{abstract}

(c) 2020 EJAL \& the Authors. Published by Eurasian Journal of Applied Linguistics (EJAL). This is an open-access article distributed under the terms and conditions of the Creative Commons Attribution license (CC BY-NC-ND) (http://creativecommons.org/licenses/by-nc-nd/4.0/).

Keywords: Intellectual humility, foreign language learning, enjoyment, anxiety

\section{Introduction}

Usually considered a virtue, humility is a characteristic that has long intrigued psychologists, theologians and philosophers, though a unanimous definition is hard to propose. Similarly, there is no universal definition of intellectual humility (IH), though several basic elements are generally agreed upon. One such characteristic is an acknowledgement and responsibility for one's intellectual shortcomings and fallibility (Leary, et al., 2017), with an openness to other viewpoints which may be in opposition to one's own (Porter \& Schumann, 2018).

\footnotetext{
* Corresponding author. Tel.:

E-mail address: smosko02@mail.bbk.ac.uk http://dx.doi.org/10.32601/ejal.834664
} 
The empirical study of intellectual humility $(\mathrm{IH})$ is still emerging and to date, there is no existing research on how IH might affect foreign language (FL) learning. Given the interface of social science disciplines and the widespread call for interdisciplinary collaboration (cf. Dewaele, 2019), the aim of the current research is to embark on an exploration of IH from an Applied Linguistics perspective. As such, we continue in the tradition of individual differences research in FL learning where researchers included variables from neighbouring disciplines (cf. Dewaele, 2009; Erten \& Erten, 2014).

Utilizing a mixed-methods approach, the questions the current research will attempt to explore are how learners' IH affects their foreign language enjoyment (FLE) and foreign language classroom anxiety (FLCA) (Dewaele \& MacIntyre, 2014). The statistical analyses will look for relationships between variables, and the qualitative component will seek traces of IH in learners' descriptions of their own experiences. The current study contributes to the emerging field of Positive Psychology in foreign language learning by further exploring the topics of FLE and FLCA, and to suggest that IH is a potential variable in the process of foreign language learning.

\section{Literature Review}

\subsection{Intellectual Humility}

The need for a middle ground between hubris and self-effacement is fundamental (Church \& Barrett, 2016; Samuelson, Church, Jarvinen, \& Paulus, 2015; Vorobej, 2011), as authors agree that one must "keep in mind the possibility that IH is a virtuous middle between two vices, intellectual arrogance and intellectual diffidence" (Barrett, 2016: 2). In disagreements, Pritchard (2018) points out that true IH involves a careful consideration of the opposing viewpoint as opposed to simply adopting a conciliatory stance. Unlike Groucho Marx's famous line of self-effacement: "Those are my principles. If you don't like them, I have others," such disingenuous concession is not indicative of IH; rather, one with IH would fairly assess one's own beliefs and the strength and evidential background of one's own argument. Hazlett's (2012) view on IH and disagreement is that one could respond with the attitude that one is fairly certain of one's epistemological belief, while acknowledging that other beliefs might also be reasonable. Hoyle et al. (2016) mirror this concept, arguing that those with IH are more willing to accept that their views and opinions might be subject to further consideration.

In their conceptualization of IH, Porter and Schumann (2018) propose that beyond a simple acceptance, an appreciation of others' viewpoints is a defining element of IH. In a study of 181 students at a community college in California, the researchers explored whether or not IH was related to openness in learning about the viewpoints of others in hypothetical classroom disagreements. They found that IH was positively associated with Need for Cognition, Openness to Experience, and Epistemic Curiosity, 
suggesting that it taps an open orientation toward thinking and learning. IH was also positively associated with a Growth Mindset of Intelligence which reflects the belief that one can develop and change one's own intelligence. It might explain the connection between IH and motivation to learn (Blackwell, Trzesniewski, \& Dweck, 2007; Krumrei-Mancuso, Haggard, LaBouff \& Rowatt, 2020; Porter \& Schumann, 2018).

Because it entails being open to others' viewpoints, Porter and Schumann (2018) contend that IH is indispensable in conflict resolution. In one study of 188 adults, the authors found that IH was closely related to modesty and openness to opposing views, though not related to low self-concept (Porter \& Schumann, 2018: 148). The authors also found that IH was "associated with having stronger learning goals" (Porter \& Schumann, 2018, p. 152).

Higher levels of IH are also associated with cognitive flexibility (Zmigrod, et al., 2019), curiosity, a love of learning and motivation to learn new things (Haggard et al., 2018). Those with IH might be more oriented towards learning, more tolerant of the unknown, and more at ease outside their comfort zones because, "simply put, learning requires the humility to realize one has something to learn" (Krumrei-Mancuso et al., 2020 , p. 155). Another aspect of IH as proposed by Roberts and Wood (2003) relates to social status. They argue that a person with sufficient IH would not be concerned with what "one's intellect or intellectual products (such as ideas and insights) bear upon one's social status" (Barrett, 2016, p. 2).

In a comprehensive analysis for the development and validation of an IH scale, Alfano et al. (2017) compared five separate studies which measured different aspects of IH, concluding that there are four essential dimensions: "Open-mindedness (versus Arrogance), Intellectual Modesty (versus Vanity), Corrigibility (versus Fragility), and Engagement (versus Boredom)" (Alfano et al., 2017, p. 1) The authors define Openmindedness, as "behavior and attitudes that reflect an acknowledgement of the limitations of one's knowledge, especially relative to others (rather than arrogance about one's intellectual capabilities and knowledge), and a desire to gain knowledge irrespective of status" (Alfano et al., 2017, p. 6) and, Engagement, which the authors define as "motivation to investigate things one doesn't understand, particularly in response to encountering ideas different from one's own" (ibid: p. 6).

Another construct to measure IH, the Comprehensive Intellectual Humility Scale (CIHS) (Krumrei-Mancuso \& Rouse, 2016) measures 4 separate but intercorrelated aspects of IH: Independence of intellect and ego, Openness to revising one's viewpoint, Respect for others' viewpoints, and Lack of intellectual overconfidence. The authors found that IH was a predictor of open-minded thinking and tolerance, though not of low self-esteem.

\subsection{Foreign Language Classroom Anxiety and Enjoyment}

Negative emotions such as anxiety have been thoroughly researched in SLA literature (Dewaele \& MacIntyre, 2014), however research on positive emotion is still 
developing and rapidly gaining traction (Dewaele, Chen, Padilla \& Lake, 2019). While positive and negative emotions in the classroom often interact, negative emotion has been described as having a narrowing effect, while positive emotion has a broadening effect (Fredrickson, 2003; MacIntyre \& Gregersen, 2012).

Dewaele and MacIntyre (2014) analyzed FLE and FLCA of 1,746 learners worldwide, utilizing a new FLE scale which included 21 items. They later defined FLE as being more than superficial pleasure but rather a complex emotion "capturing interacting dimensions of challenge and perceived ability" (Dewaele \& MacIntyre, 2016, p. 216). Using an analogy from sports, they explain that "it might be pleasurable to win a game by a wide margin but it is not necessarily a game anyone enjoys; alternatively, it is enjoyable to play well in a closely contested match where success might mean playing well and either winning or losing" (p. 217). The FLE scale was combined with an 8-item FLCA scale that was extracted from the Foreign Language Classroom Anxiety Scale (FLCAS) (Horwitz, Horwitz \& Cope, 1986) and corresponded to the original structure. FLCA was defined by Horwitz (2017) as an anxiety that people who learn a language experience "because of distress at their inability to be themselves and to connect authentically with other people through the limitation of the new language" (p. 41). Dewaele and MacIntyre (2014) found that FLE and FLCA were negatively correlated (though the effect size was small) and the investigation into the sources of FLE and FLCA revealed that higher FLE and lower FLCA were linked to being older, having a tertiary education, and having a higher degree of multilingualism. Female participants reported higher levels of both FLE and FLCA than male participants. The qualitative component of the study was based on feedback to an open-ended question which asked learners to describe an episode from their class that had been particularly enjoyable, of which 1,076 of the 1,740 respondents answered. The responses described activities that typically involved a degree of learner autonomy such as class debates, presentations, and activities that involved group collaboration. Teachers were often mentioned for their use of humour to lighten the mood and lessen potential embarrassment from mistakes and other potential losses of face.

While FLE and FLCA are related, they are predicted by different variables, with FLE being more attributed to the teacher and FLCA to the learner's self (Dewaele \& Dewaele, 2020; Dewaele \& MacIntyre, 2019; Dewaele, Witney, Saito \& Dewaele, 2018).

Dewaele and MacIntyre's (2014) work illustrated the important effect of a social dimension, namely how learners view their own social standing in relation to their peers. Higher FLE and lower FLCA depended on the strength of the bonds formed with classmates in the classroom and their place in the group hierarchy. As with FLE, the role of teachers emerged repeatedly in respondents' narratives, which is not surprising given that teachers can help students manage their anxiety by creating an atmosphere that is emotionally positive and supportive (Arnold, 1999; Borg, 2006; Dewaele, 2015; Dewaele \& MacIntyre, 2016; Dewaele et al., 2018; Dewaele, Magdalena Franco \& Saito, 2019; Dörnyei \& Csizér, 1998; Dörnyei \& Murphy, 2003; 
Gregersen \& MacIntyre, 2014). Dewaele \& Dewaele (2020) analysed FLE and FLCA from 40 British FL learners who had two different teachers for the same FL. While levels of FLCA were identical with both teachers, students reported significantly more FLE with the Main Teacher than with the Second Teacher. The authors concluded that FLE is more teacher-specific than FLCA, which reinforces the finding in Dewaele et al. (2018) that teachers can boost their students' levels of FLE more easily than lower their FLCA.

Botes, Dewaele and Greiff (2020) set out to determine the factor structure of FLE in the Dewaele and MacIntyre's (2014) dataset and to develop a psychometrically strong short form of the questionnaire (S-FLES). Exploratory and confirmatory factor analysis revealed one higher-order factor (FLE) and three lower order factors: Teacher Appreciation, Personal Enjoyment, and Social Enjoyment. The S-FLES was validated and the fit statistics for the factor structure indicated close fit.

\subsection{Hypothesizing about IH in the FL classroom}

Researchers found that IH predicts less overclaiming of one's own knowledge (Alfano, et al., 2017; Krumrei-Mancuso et al., 2020). In the field of FL learning, this could be manifest in a learner's realistic assessment of their own proficiency level in the FL, and an admission of linguistic deficiencies and shortcomings. One could expect that a language learner with high IH might be more likely to ask questions when not understanding something in the FL. Since IH also involves a sense of independence of intellect and ego, a FL learner with a high level of IH might be less vulnerable to the opinion of others, more willing to take risks, and less anxious in using the FL.

Since those with high IH tend to be more willing to pay attention to, and even appreciate opinions and beliefs that are different than their own, learners with high IH might enjoy lively classroom debates and feel less threatened by opposing views. Those with IH might also be more helpful and more inclined to collaborative work and group problem solving, which could help to foster social cohesion in the FL classroom.

Since IH has not been previously studied in relation to FL learning, it is difficult to propose a directional hypothesis on how it might influence FLE and FLCA. However, since FLE is "most often attributed to the teacher while FLCA experiences were most frequently linked to the self" (Dewaele \& MacIntyre, 2019), one might speculate that IH would have a more marked effect on FLCA than on FLE. Because IH has been associated with open-mindedness across various contexts (Krumrei-Mancuso et al., 2020), it could translate in a greater tendency to appreciate humour and spontaneity in the FL classroom, which could theoretically increase FLE. Moreover, IH has been associated with more prosocial types of thinking, such as tolerance (Krumrei-Mancuso \& Rouse, 2016), and a sense of empathy and altruism (Krumrei-Mancuso, 2017), which could strengthen a sense of unity and social bonding in the FL classroom, thereby increasing FLE and mitigating FLCA. Past research has clearly demonstrated that social standing among peers is a strong predictor of FLCA 
(Dewaele \& MacIntyre, 2014; Dewaele, et al., 2018), therefore it might be reasonable to expect that those with IH would experience less FLCA, as IH has been linked to less concern over one's social status (Barrett, 2016; Roberts \& Wood, 2003).

Research Questions

1. RQ1. What is the relationship between overall IH and FLE, as well as IH subscales and FLE subscales?

2. RQ2. What is the relationship between overall IH and FLCA, as well as IH subscales and FLCA?

3. RQ3. Is a sense of IH expressed in respondents' descriptions of their experiences of FLE and FLCA, and if so, which aspects of IH are most prominent?

\section{Method}

The research design and questionnaire obtained ethics approval from the authors' research institution. Each participant's individual consent was obtained at the start of the survey. A pilot test was run on a small group of participants, who indicated that certain questions were unclear or ambiguously worded. The survey was revised accordingly, and the final version made with Google Forms was posted on various social media outlets. The call for participation was distributed to contacts, colleagues and friends. The survey remained online from November 2019 until January 2020. This method was chosen because it allows for easier collection of data across countries and demographic groups and because "data obtained in this way have been shown to be valuable and can come closest to catching elusive phenomena" (Dewaele, 2019, p. 77).

\subsection{Participants}

A total of 163 participants took part (females $=108$, males $=51$, gender unspecified =4). All participants were Spanish L1 speakers who were enrolled in an English class at any level of proficiency. The types of English classes ranged from universities to professional/continuing education to language schools. Ages ranged from 16 to 65 $($ Mean $=31, S D=11.7)$, and the age of onset of learning English ranged from 3 to 64 $($ Mean $=15.2, S D=11.5)$. Asked about their relative standing in the English class $(1=$ much lower than average, $5=$ much higher than average), responses ranged from 1 to $5($ Mean $=3.2, S D=1.1)$ Similarly, when asked how they define their level of English in general $(1=$ basic, $5=$ advanced $)$, responses ranged from 1 to 5 . (Mean $=3.2, S D=$ 1.0). Respondents reported 17 different nationalities: Spain $(n=78)$, Colombia $(n=$ $31)$, Mexico $(n=15)$, Peru $(n=7)$, Argentina $(n=4)$, and smaller numbers from Guatemala, Bolivia, Ecuador, Honduras, Nicaragua, El Salvador, Venezuela, Panama, Costa Rica, Chile, Morocco, Andorra and USA.

\subsection{Instrument}


The entire survey was administered in Spanish. Original constructs, as outlined below, were translated from English to Spanish. All open-ended questions were written by respondents in Spanish, and then translated and reported in English.

The research instrument used a mixed-methods approach to combine both emic and etic perspective (Dewaele, 2019), collecting quantitative and qualitative data at the same time in a convergent parallel design (Creswell \& Plano Clark, 2011). The quantitative part included correlation analyses and multiple regression analyses, which allows for flexibility in measurements and types of variables (Plonsky \& Ghanbar, 2018). The qualitative component was meant to add a crucial human touch to the quantitative data, providing context and deeper insight (Dewaele \& MacIntyre, 2014), as well as the elaboration of specific topics of interest (Creswell \& Plano Clark, 2011).

The first part of the survey consisted of 9 items to collect basic demographic information such as age, gender and nationality. The second part of the survey used the Comprehensive Intellectual Humility Scale (CIHS) (Krumrei-Mancuso \& Rouse, 2016): "The full-scale CIHS can be used to provide an overall score for IH...Where desirable, individual subscale scores can be taken into consideration as well" (Krumrei-Mancuso \& Rouse, 2016, p. 220). The CIHS is a self-report construct which consists of 22 items measuring IH. Responses were measured on a 5-point Likert scale ranging from 1 (strongly disagree) to 5 (strongly agree). Negatively worded items were reverse coded. Average scores ranged from 3.09 to 5 (Mean $=4.02$, $\mathrm{SD}=.36$ ). Reliability was good (Cronbach's a $=0.748$ ). The CIHS accounts for both social and cognitive aspects of $\mathrm{IH}$, which make it a good fit in a study on FL learning in a classroom setting.

The CIHS can be divided into four subscales:

- Independence of Intellect and Ego (5 items) (Mean $=4.05, S D=.68$, Cronbach's $a=$ 0.914).

- Openness to Revising One's Viewpoint (5 items) (Mean $=3.96, S D=.63$, Cronbach's $a=0.872$ ).

- Respect for Others' Viewpoints (6 items) (Mean $=4.32, S D=.54$, Cronbach's $a=$ 0.926).

- Lack of Intellectual Overconfidence (6 items) (Mean $=3.77, S D=.55$, Cronbach's $a$ $=0.822)$.

As a self-report measure, the CIHS offers "more accurate assessment of the intrapsychic feelings, attitudes and beliefs underlying IH, in addition to assessing behavioural components of IH" (Krumrei-Mancuso \& Rouse, 2016, p. 210). Self-report measures are not without biases and a possible lack of awareness on the part of respondents (Bollinger \& Hill, 2012; Duckworth \& Yeager, 2015), however taking into account that every measure of assessment has certain deficiencies, this construct was deemed a good fit for the current research based on its versatility and internal consistency. The CIHS was also chosen because of its relative simplicity. Respondents for the present study were invited to participate regardless of their formal education 
level or their proficiency in English, and "the scale requires only 4 years of education to be readable" (Krumrei-Mancuso \& Rouse, 2016, p. 220).

The third part of the survey measured enjoyment using the S-FLES (Botes et al., 2020), consisting of 9 items. All questions were positively worded and measured on a 5 -point Likert scale ranging from 1 (strongly disagree) to 5 (strongly agree). FLE scores ranged from 1.40 to 5, Mean $=3.76, S D=.76$, Cronbach's $a=.884$.

The FLE subscales are:

- Personal Enjoyment (3 items) (Mean $=3.96, S D=.82$; Cronbach's $\alpha=.793$ )

- Social Enjoyment (3 items) (Mean $=3.39, S D=.88$; Cronbach's $\alpha=.758$

- Teacher Appreciation (3 items) $($ Mean $=3.93, S D=1.05$, Cronbach's $\alpha=.927)$

The fourth part of the survey consisted of 8 items measuring respondents' levels of Foreign Language Classroom Anxiety (FLCA), using items extracted from the FLCAS (Horwitz et al., 1986), which were also used by Dewaele and MacIntyre (2014, 2016). Two positively oriented items were recoded. Scores ranged from 1 to 5 , Mean $=3.09$, $S D=.91$, Cronbach's $\alpha=.852$.

Normal distribution was checked with QQ plots for IH, FLE and FLCA (Figures 13). Aside from some outliers on the positive and negative ends of the FLE and FLCA scales, the scores seemed normally distributed and the more powerful parametric statistics were chosen.

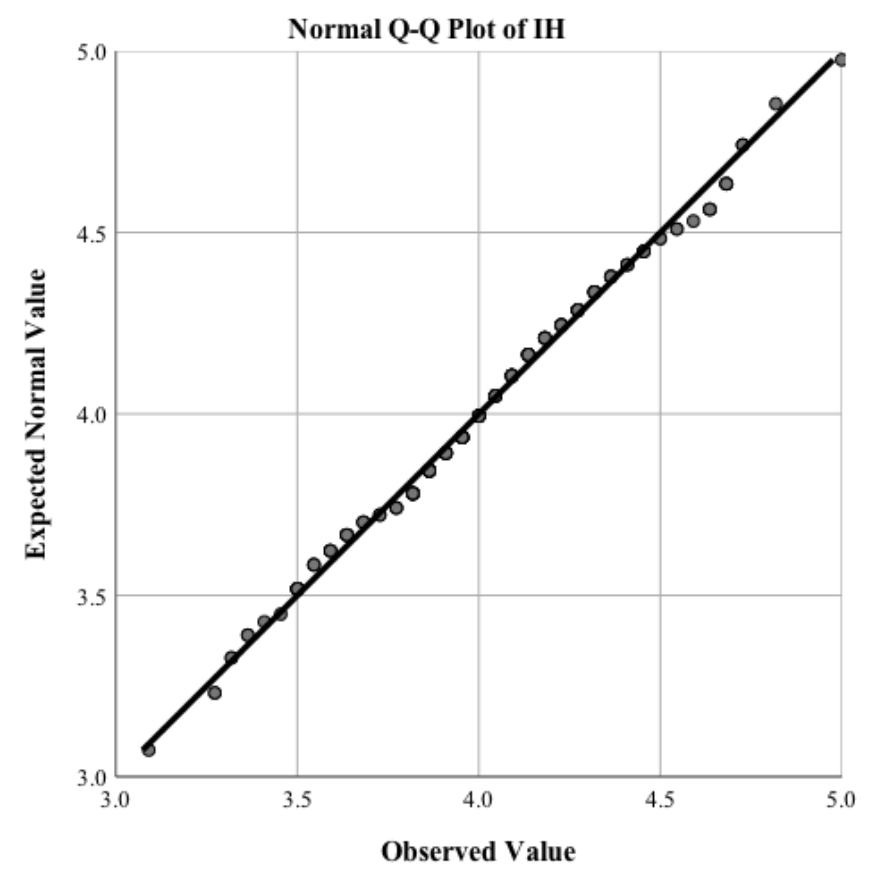

Figure 1. Q-Q Plot for IH 


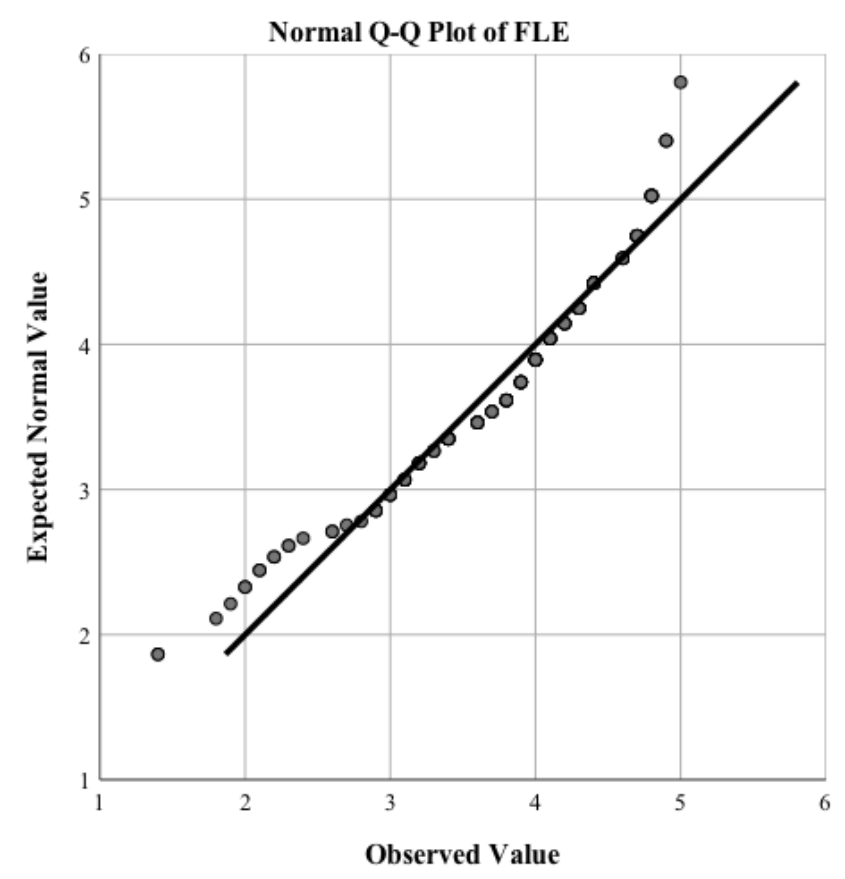

Figure 2. Q-Q Plot for FLE

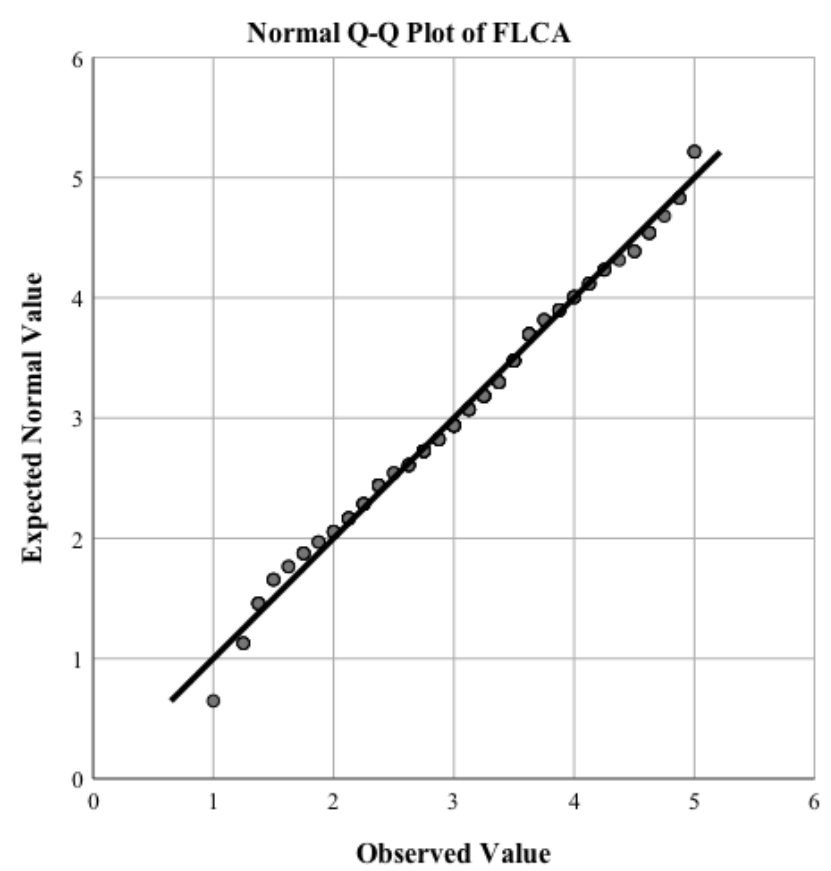

Figure 3. Q-Q Plot FLCA

The fifth and final section of the survey consisted of three open-ended questions, meant to add more granular detail to the quantitative data and gain a deeper understanding of respondents' experiences in their own words. The open-ended questions, which elicited a written response, were: 
1. Describe an episode in your English class which you really enjoyed. Use as much detail as possible. [Based on Dewaele \& MacIntyre, 2014].

2. Describe an episode in your English class that caused you anxiety. Use as much detail as possible.

3. What are your biggest strengths and weaknesses in learning English?

\section{Results}

\subsection{Quantitative analysis}

Pearson correlation analysis showed no significant relationship between total IH and total FLE $(r=-.056, p=n s)$. However, a significant negative relationship was found between the IH subscale Lack of intellectual overconfidence and the FLE subscale of FLE Personal (Table 1). According to Plonsky and Oswald (2014) this correlation represents a small effect size $(r=.25)$. In other words, the higher the lack of overconfidence, the less FLE Personal experienced.

Table 1. Pearson correlations between total IH, IH subscales and FLE subscales

\begin{tabular}{llll}
\hline Subscale & Personal & Social & Teacher Appreciation \\
\hline Independence of Intellect and Ego & .109 & -.076 & .057 \\
Openness to Revising Own Viewpoint & .026 & -.029 & .092 \\
Respect for Others' Viewpoints & .052 & -.102 & .050 \\
Lack of Intellectual Overconfidence & $.245^{* *}$ & -.148 & -.070 \\
\hline$* * \mathrm{p}<.01$ &
\end{tabular}

A scatterplot of FLE Personal and Lack of intellectual overconfidence (Figure 4) illustrates the negative correlation, indicating that those who lack intellectual overconfidence experience less Personal enjoyment in class.

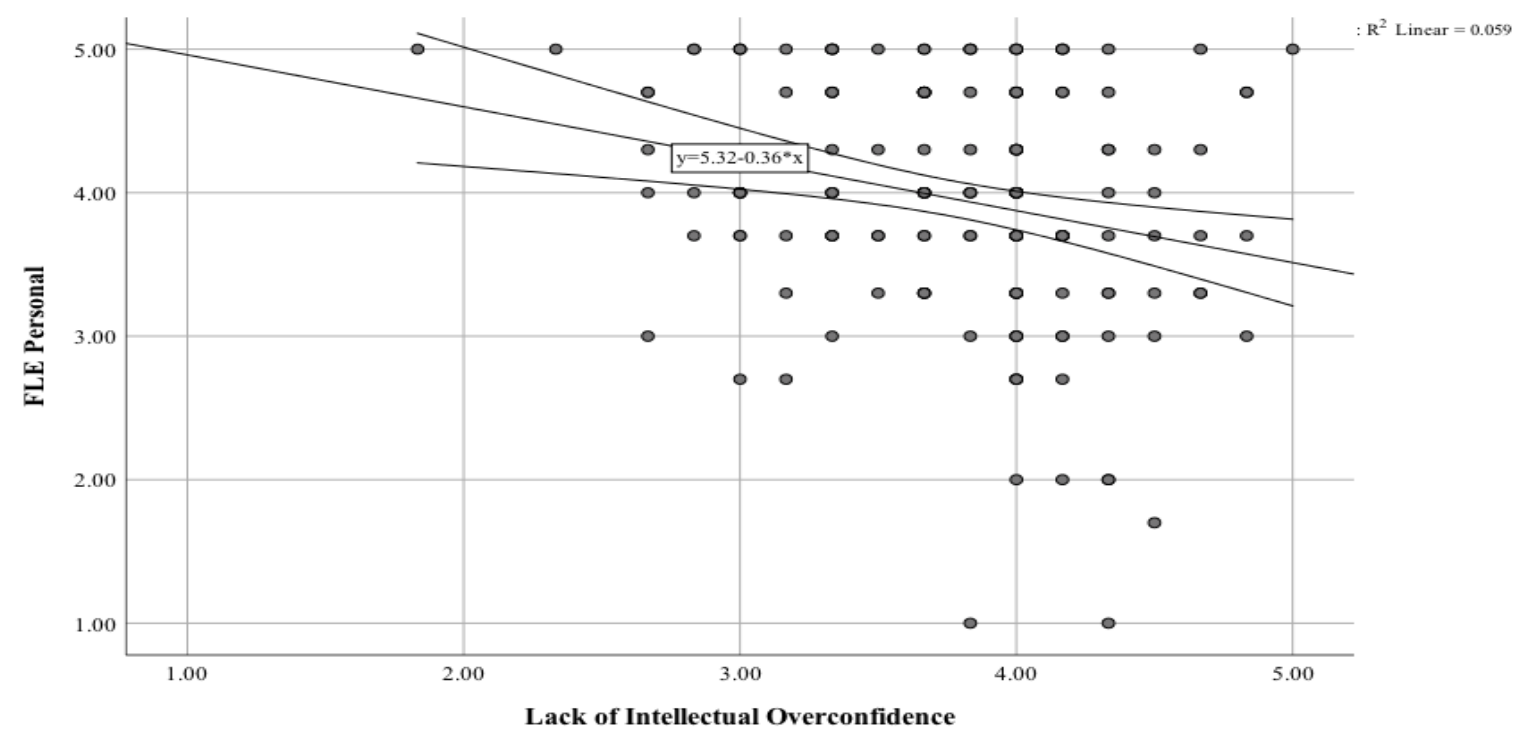


Figure 4. Scatterplot of FLE Personal and Lack of Intellectual Overconfidence (with 95\% confidence intervals)

A Pearson correlation analysis showed no significant relationship between total IH and FLCA $(r=-.056, p=n s)$. However, the IH subscale 'Independence of intellect and ego 'is negatively correlated with FLCA and the subscale 'Lack of intellectual overconfidence 'is positively correlated with FLCA, representing a very small effect size (see Table 2, Figures 5-6).

Table 2. Pearson correlations between IH subscales and FLCA

\begin{tabular}{lc}
\hline IH Subscale & FLCA \\
\hline Independence of Intellect and Ego & $-.217^{* *}$ \\
Openness to Revising Own Viewpoint & .033 \\
Respect for Others' Viewpoints & .029 \\
Lack of intellectual Overconfidence & $.155^{*}$ \\
\hline
\end{tabular}

$*$ p $<.05, * * p<.01$

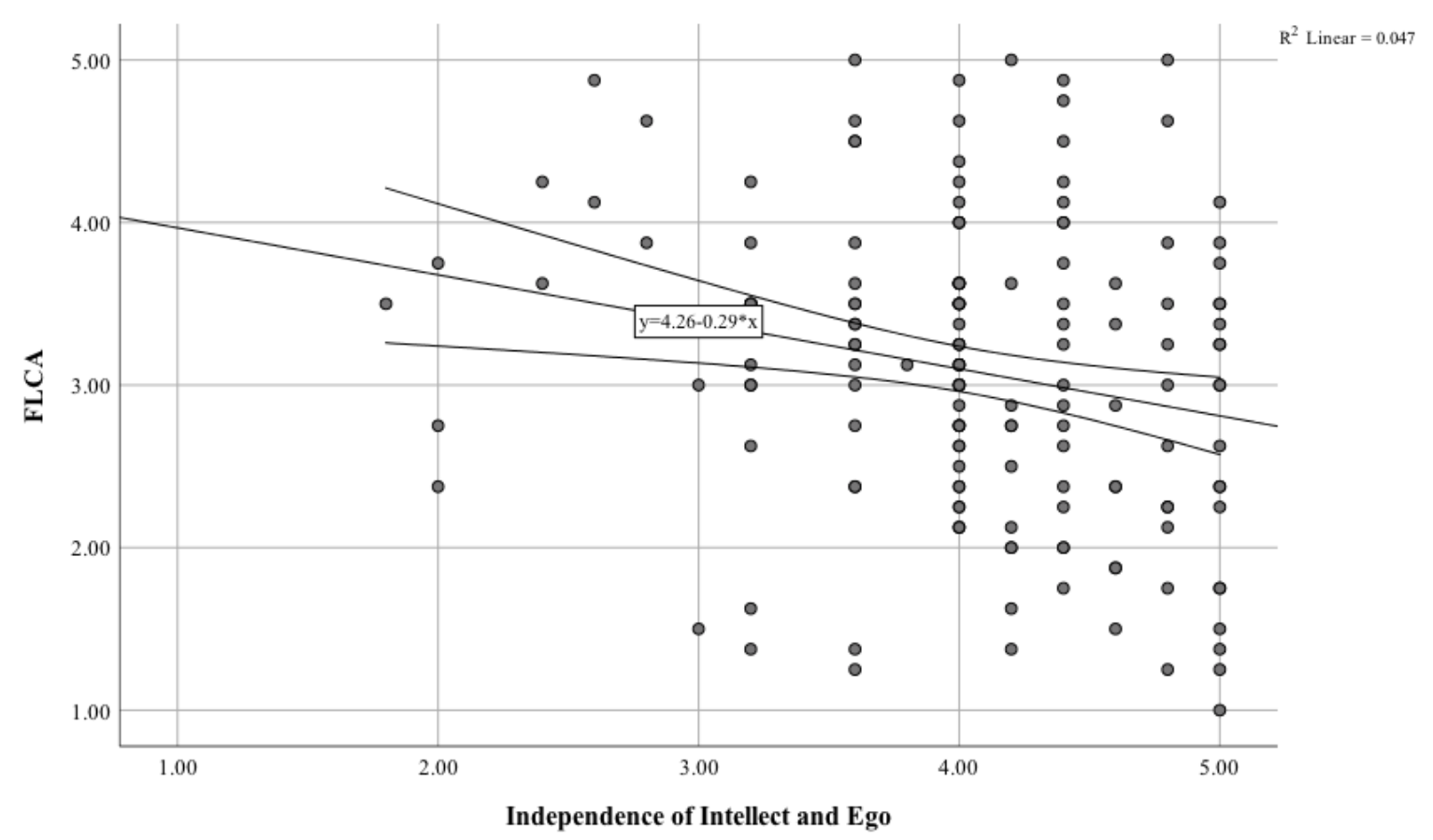

Figure 5. Scatterplot of FLCA and Independence of Intellect and Ego (with 95\% confidence intervals) 


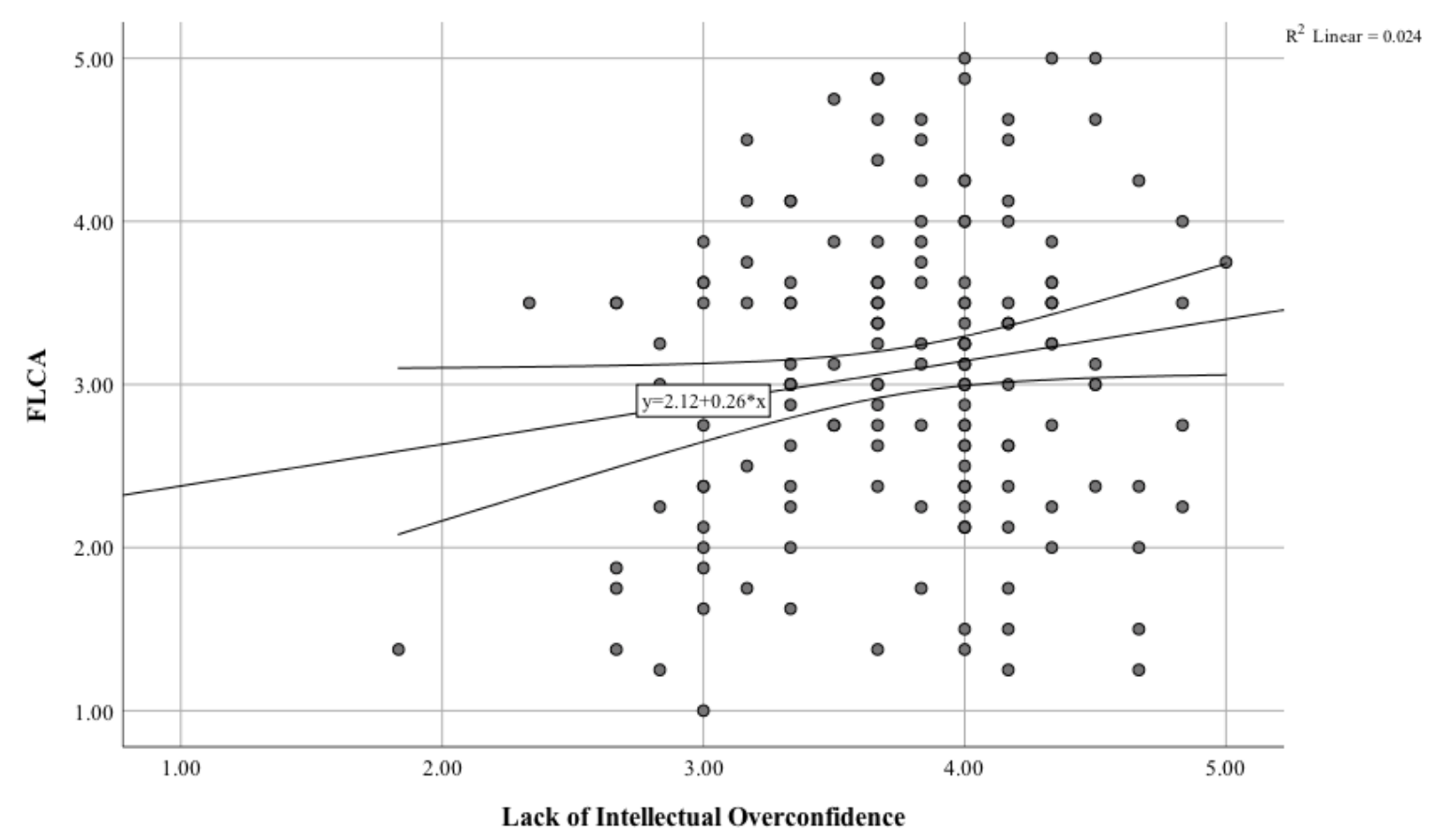

Figure 6. Scatterplot of FLCA and Lack of Intellectual Overconfidence (with 95\% confidence intervals)

The two variables that had a significant relationship with FLCA were included in a multiple linear regression analysis (Table 5). It revealed a significant regression equation for FLCA with the two variables predicting 7\% of the variance (Adjusted $R^{2}$ $=6.1, F(2,160)=6.3, p<.002)$. The strongest predictor of FLCA was Independence of Intellect and Ego (Beta $=-.220, t=-2.89, p<.004)$, followed by Lack of Intellectual Overconfidence (Beta $=.160, t=.210, p<.037)$. This effect size is small (Plonsky \& Ghanbar, 2018). In other words, participants with high levels of Independence of Intellect and Ego suffered less from FLCA while those with high levels of Lack of Intellectual Overconfidence suffered more from FLCA.

\subsection{Qualitative analysis}

Three open-ended questions asked respondents to describe their experiences in their own words. Because the questions were obligatory, all 163 respondents answered, producing 9,561 words in total, with responses of varied lengths. Responses were chosen based on relevance and interest.

\subsubsection{IH and FLE}

When asked to describe an enjoyable episode in English class, certain themes were recurrent in the respondents 'answers. In general, humour, playfulness and unguarded spontaneity on the part of the teacher were often cited, which accords with past research on FLE (Dewaele, 2015; Dewaele \& Dewaele, 2017; Dewaele et al., 2018; Dewaele \& MacIntyre, 2014; Dewaele, Magdalena Franco \& Saito, 2019), as well as past research on the effect of positive emotional contagion in the classroom 
(Dewaele \& Li, 2020; Dresel \& Hall, 2013; Frenzel \& Stephens, 2013; Moskowitz \& Dewaele, 2019).

Evidence also emerged of the different domains of IH in relation to FLE. One respondent makes a particularly interesting point about how respectfully disagreeing with others 'opinions evinced a strong sense of enjoyment. Interestingly, in some responses the teacher also seems to be promoting IH in the students by encouraging them not to take disagreements personally. This could be interpreted as teacher promotion of the IH domain of Independence of intellect and ego in students.

Respondents described the joy of learning new things and motivation to learn, which is consistent with a key characteristic of IH (Blackwell, Trzesniewski, \& Dweck, 2007; Krumrei-Mancuso et al., 2020, Porter \& Schumann, 2018). In addition, there were descriptions of a sense of social enjoyment and bonding with peers, which might relate to the IH characteristic of not being overly concerned with social status (Roberts \& Wood, 2003):

$\mathrm{AB}, 21$, Spain: I have a class called oral practice, once the teacher arrived and gave us some topics for us to make debates. [Topics] were politics, human rights or bizarre as witchcraft. I remember very well that the teacher told us to express our opinions and if we agreed or not, we would not feel personal. That exercise gave us confidence to improve our orality, we laughed when we debated and did not agree on aspects since we all wanted to talk and contradict the other (in a respectful and friendly way) to the point that we did not want to leave the room to continue doing the activity.

MS, 19, Spain/Netherlands: They taught us about phonetic symbols and how they were read and absolutely nobody had any idea of anything. It was very fun to see that nothing happens for not knowing about a subject, that it never hurts to know new things and that it does not matter the level in which you are to learn basic things that at the same time they went through to study.

IH and a sense of FLE is also seen in responses about feeling a lack of social pressure in the classroom, and consequently, a sense of unity. This is reminiscent of the findings of Dewaele et al. (2018) that FLE is sometimes experienced by learners as an absence of anxiety and of joint purpose. The crucial role of the teacher in promoting FLE was cited repeatedly by respondents, squaring with previous research on emotion in the classroom. One respondent described her teachers use of 'bad' teacher jokes to lighten the mood of the classroom:

RF, 18, Spain: An old teacher, he told us his experiences, bad jokes and made random comments to get us to smile, because he knew that we were very heavy class.

JA, 52, Spain: Interaction with teachers is important. When they correct me in a private talk and you think that the class has not done well to correct you several times and they evaluate you as you have made a great effort. 
JG, Gender unspecified, 19, Spain: In an English course in Madrid, the teacher made us repeat the alphabet in turn, each person said a letter, a, b, c, d, ... until we reached the $z$. The goal was to speak as quickly as possible and whoever took the shortest time won. (...). I didn't feel any social pressure of having to stand out or match the rest of my classmates. The atmosphere was cozy, there was a lot of confidence among the entire class because the teacher made us do dances from the beginning to lose the shame among all.

NA, 19, Colombia: It was last semester, I had a very dynamic teacher, we did very simple activities which helped us all learn more. Since there were boys who had almost perfect English, people like me who didn't study before in any institution felt insecure. What the teacher did was put an activity in which no matter your level of English you could participate in it, so we all had a lot of fun.

Another salient theme in the descriptions of FLE is the enjoyment of classroom debate. This connection is noteworthy in relation to $\mathrm{IH}$ as it implies not taking disagreement too personally (Independence of intellect and ego) and amicable, nonthreatening disagreement (Respect for others 'viewpoints):

EV, 24, Spain: Possibly, one of the English classes I enjoyed most was a group discussion. In this debate, a critical situation was exposed that forced students to choose a limited number of tools and people (different trades) to start a new life on a desert island. This resulted in an intense conversation with varied arguments and opinions. Each group should reach a conclusion and expose it in front of the other groups.

DA, 17, Colombia: In a class we did socialization exercises and it was interesting to share ideas and different points of view with my classmates regarding different topics.

HG, 20, Colombia: Holding a debate about an interesting topic in which comments were seen in favour was one of the best classes I have had, since it was based on talking about something that is important to us as people.

\subsubsection{IH and FLCA}

The qualitative data indicated that fear of embarrassment among peers is a commonly reported source of anxiety among learners, underscoring the wellestablished link between social standing and FLCA. As evident in the following responses, learners feel particularly susceptible to anxiety when asked to speak or answer questions in front of the class, for fear of embarrassing themselves or being negatively judged by their peers. This might be understood as a deficiency of the IH characteristic of Independence of intellect and ego:

JP, 19, Spain: In English lexicology and morphology classes, my teacher is quite strict. I am very bad at the subject, but also always put exercises on the board and call us to do them. Apart from the fact that I feel that she will think that I am stupid if I make a mistake, I also think that the partners will laugh at me etc. 
MS, 20, Colombia: It was the class where we had to present the oral part of a course. We had to make a sketch. My group and I did not prepare the presentation well, we were not clear about the situation nor did we know our dialogues but we still decided to go, it went badly and we made a fool of ourselves.

SM, 26, Spain: To speak in English in front of my classmates. It is something that makes me feel anxious forever. I don't think I have a bad level of English, but it's true that I don't feel comfortable if I know that there are people with a good level of English who are listening to me.

JG, 19, Spain: When you have to speak out loud, in front of the public, during presentations I often feel that they don't care what I'm going to say, or that what I'm saying is boring. Above all, people's faces make me very nervous because some people frown too much and I feel they are judging me by my level of English.

Also expressed is anxiety caused by being caught off guard or put on the spot and being compared to other students in the class:

MO, 18, Spain: When I feel more anxious in my English classes is when we do oral activities during class and the teacher calls me to come out in front of everyone and speak improvisedly, without having a script, or to do something that I cannot have studied and thought carefully about What am I going to do and say? In front of a group of people I find it hard to behave naturally and think clearly.

Although pressure to save face among peers is a common thread among responses to FLCA, teachers were also occasionally mentioned as both causing and decreasing classroom anxiety. Several respondents mentioned a fear of being ridiculed in front of the class by the teacher. Conversely, as seen in the following response, the use of teacher humor to assuage classroom anxiety was also mentioned:

MM, 19, Spain: One day, we were talking about body language in oral presentations. The teacher, to correct our mistakes and be more professional and less nervous before the public, asked us to get up, and improvising, to tell our classmates our reasons to be studying the career we had chosen. It was a very enriching activity, which helped us to know our mistakes and learn from them, as well as laugh a lot while we did it because of the teacher's comments.

\section{Discussion}

The first question dealt with the relationship between IH and FLE. No significant relationship emerged between overall IH and overall FLE, however the IH subscale Lack of intellectual overconfidence was significantly negatively correlated to FLE Personal. This might suggest that those who are not overconfident about their ideas and intellectual abilities might experience slightly less enjoyment in the FL classroom than those who are overconfident. The FLE domains of FLE Social and FLE Teacher Appreciation were not significantly linked to any subscale of $\mathrm{IH}$, possibly because the emotions arising from social contact with peers and teachers are more remote from the very ego-centered dimensions of IH. Overconfidence might be a risky trait in 
general, but one might argue that overconfidence is a useful trait in classroom interaction as it implies active participation and maybe even a sense of recklessness and linguistic experimentation, which is at the heart of FLE (cf. Boudreau et al., 2018; Dewaele \& MacIntyre, 2014). Too little confidence in one's ideas and intellectual abilities, to which could be added communicative abilities, might stop one from joining the discussion and enjoying the process of trying out a new persona in a new language. In other words, too much humility might be a silencer.

The second question explored the relationship between IH and FLCA. Again, there was no significant connection between overall IH and FLCA, though the findings revealed that the IH subscale of Independence of intellect and ego was negatively correlated with FLCA, meaning that those who feel less personally attacked or threatened by disagreement or difference of opinion tend to experience less anxiety. It suggests that those who are confident about their intellectual (and communicative) abilities have a mental shield that protects them from FLCA. The subscale included questions such as I feel small when others disagree with me on topics that are close to my heart. This finding aligns with the notion that because FL use presents a potential loss of face, those who are less likely to take things personally and feel intimidated by adversity might feel less anxiety. Similarly, learners who score higher on Psychoticism (i.e. those who do not mind much what other people think of them) have been found to suffer less from FLCA (Dewaele, 2013).

The IH subscale of Lack of intellectual overconfidence was positively linked with FLCA, indicating that learners who do not believe that their ideas are inherently better than others might experience slightly more anxiety. The explanation for this relationship is probably linked to what we argued earlier about FLE. Being too humble about one's intellectual (and communicative) abilities means too much doubt about being able to use the FL effectively and a fear of errors and disfluencies. It entails a preference to remain passive during discussions, pushing one in the role of observer rather than participant, and hence not joining in group bonding that is the source of FLE and an excellent antidote to FLCA. The two IH subscales taken together predicted a small amount of variance in FLCA.

The results of the first and second research questions indicate that the IH subscale 'Lack of intellectual overconfidence 'has a negative effect on FLE and a positive effect on FLCA. This finding could be taken to mean that being overconfident might in fact be a good thing in the FL classroom. However, the IH subscale of Independence of intellect and ego negatively predicted FLCA, indicating that those who are fully aware of their intellectual (and communicative) abilities, and not inclined to hide them, may suffer less from FLCA because their ego can deal with unexpected problems and criticisms

In the open-ended questions for FLE, respondents repeatedly wrote about enjoying debates in the classroom and the joy of learning new things. The role of the teacher was mentioned frequently as a factor influencing FLE. Although the teacher's role in FLCA was mentioned both positively and negatively, responses overwhelmingly cited 
peers as a main factor in FLCA confirming previous research (Dewaele \& Dewaele, 2017, 2020).

Interestingly, the qualitative data seem to support the quantitative finding of a positive relationship between 'Lack of intellectual overconfidence 'and FLCA. Being humble may be considered a virtue, but some overconfidence might not be a sin the FL classroom as it could help control FLCA and boost FLE.

The negative relationship between Independence of intellect and ego and FLCA was apparent in the open-ended responses as well. Respondents who felt that making mistakes presented a threat to their sense of self reported anxiety and fear of humiliation. This self-consciousness in FL classrooms could be understood as a lack of independence of intellect and ego.

Overall, results from the questionnaire point to a complex and nuanced relationship between IH and FL learning. While IH may generally be considered a virtue in other domains such as promoting tolerance in political debate, in the emotionally charged arena of the FL classroom it seems to be a mixed bag, with both positive and negative effects on learner emotions.

Research on IH is quickly expanding though it is still in its relative infancy. One area in particular that deserves attention is the role of $\mathrm{IH}$ in different cultural settings, especially in non-Western settings (Alfano et al., 2017).

One limitation of the research design is that the teacher was largely left out of the equation. Past research has shown that how students view teachers affect their FLE, but is not predictive of FLCA (Dewaele \& Dewaele, 2020; Dewaele et al., 2019). And indeed, in the current study the teacher's indispensability in promoting and maintaining FLE was apparent throughout the respondents 'written answers to the open-ended questions. Future research might consider taking the teacher into account, perhaps even testing the teacher's IH as a possible predictor of their own emotions and students 'FLE and FLCA.

Future research might explore the complex personal underpinnings of IH in relation to FL learning. The data presented in the current paper suggest that IH might be simultaneously a boon and a bane to FL learning, affecting different aspects differently. It would also be worthwhile to further explore the connection between IH and other aspects of FL learning in diverse contexts and learning situations.

\section{Conclusion}

This study looked at how IH affects FLE and FLCA among Spanish EFL learners. No relationship emerged at the global level, but a number of significant links were found between the subscales of IH, FLE and FLCA. Participants who scored higher on Intellectual overconfidence also experienced significantly more ego-oriented personal enjoyment and suffered less from FLCA. Participants with higher levels of Independence of intellect and ego were also significantly less likely to suffer from FLCA. 
Echoes of the statistical findings were found in the qualitative data. Crucially, confidence emerged as an important attribute in controlling FLCA and a pre-requisite for FLE. Participants established connections between some IH traits, FLE and FLCA that did not emerge in the quantitative analyses. For example, the enjoyment of lively classroom debates and the respect of others 'viewpoints, which aligns with Porter and Schumann's research (2018). Additionally, participants with higher IH levels seemed more aware of their own limitations, a finding that also aligns with previous research (Hoyle et al., 2016).

The results of the present study are modest, suggesting that overall IH has a relatively limited effect on learners 'classroom emotions. This could be linked to the very construct of IH adopted in this paper. It seems that one aspect of IH, namely selflessness, is less relevant to classroom emotions, while the other aspect of $\mathrm{IH}$, having an accurate view of one's own worth and abilities, might temper both enjoyment and anxiety. The mixed results of the current study underscore the complexity of the interactions between personality traits and classroom emotion in FL classes.

\section{The Research and Publication Ethics Statement}

The Ethics Committee/Board approval for this study was obtained from School of Social Sciences, History and Philosophy, Birkbeck, University of London on 11/04/2019. No ethical considerations were violated in this study.

\section{The Conflict of Interest Statement}

In line with the statement of Committee on Publication Ethics (COPE), we hereby declare that we had no conflicting interests regarding any parties of this study.

\section{References}

Alfano, M., Iurino, K., Stey, P., Robinson, B., Christen M, Yu F., \& Lapsley, D. (2017). Development and validation of a multi-dimensional measure of intellectual humility. PLoS ONE, 12(8), e0182950.

Arnold, J. (2011). Attention to affect in language learning. Anglistik. International Journal of English Studies, 22, 11-22.

Arnold, J. (Ed.) (1999). Affect in Language Learning. Cambridge: Cambridge University Press.

Barrett, J. (2017). Intellectual humility. The Journal of Positive Psychology, vol.12, no. 1, 1-2.

Blackwell, L., Trzesniewski, K., \& Dweck, C. (2007). Implicit theories of intelligence predict achievement across an adolescent transition: A longitudinal study and an intervention. Child Development, 78, 246-263.

Bollinger, R. A., \& Hill, P. C. (2012). Humility. In T. G Plante (Ed.), Religion, spirituality, and positive psychology: Understanding the psychological fruits of faith (pp. 31-48). Santa Barbara, CA: Praeger.

Borg, S. (2006). Teacher cognition and language education: Research and practice. London: Continuum.

Botes, E., Dewaele, J.-M., \& Greiff, S. (2020). The Development of a Short-Form Foreign Language Enjoyment Scale. Unpublished manuscript. 
Church, I.M. \& Barrett, J.L. (2016). "Intellectual Humility". In E. L. Worthington, D. E. Davis \& J. N. Hook (eds.), Handbook of Humility. Abingdon: Routledge.

Creswell, J.W. \& Plano Clark, V.L. (2011). Designing and Conducting Mixed Methods Research. Thousand Oaks, CA: Sage.

Dewaele, J.-M. (2009). Individual differences in Second Language Acquisition. In W. C. Ritchie \& T. K. Bhatia (Eds.), The New Handbook of Second Language Acquisition. Bingley (UK): Emerald, pp. 623-646.

Dewaele, J.-M. (2015) On emotions in foreign language learning and use. The Language Teacher 39 (3), 13-15.

Dewaele, J.-M., Chen, X., Padilla, A.M. \& Lake, J. (2019) The flowering of positive psychology in foreign language teaching and acquisition research. Frontiers in Psychology. Language Sciences, 10, 2128. Doi: 10.3389/fpsyg.2019.02128

Dewaele, J.-M. \& Dewaele, L. (2017). The dynamic interactions in foreign language classroom anxiety and foreign language enjoyment of pupils aged 12 to 18. A pseudo-longitudinal investigation. Journal of the European Second Language Association, 1, 11-22.

Dewaele, J.-M. \& Li, C. (2020). Emotions in Second Language Acquisition: A critical review and research agenda. Foreign Language World [Chinese 外语界], 196(1), 34-49.

Dewaele, J.-M., Magdalena Franco, A. \& Saito, K. (2019). The effect of perception of teacher characteristics on Spanish EFL Learners 'Anxiety and Enjoyment. The Modern Language Journal, 103(2), 412-427.

Dewaele, J.-M. \& Dewaele, L. (2020). Are foreign language learners 'enjoyment and anxiety specific to the teacher? An investigation into the dynamics of learners 'classroom emotions. Studies in Second Language Learning and Teaching, 10(1), 45-65.

Dewaele, J.-M. \& MacIntyre, P.D. (2014). The two faces of Janus? Anxiety and enjoyment in the foreign language classroom. Studies in Second Language Learning and Teaching, 4, 237-274.

Dewaele, J.-M., \& MacIntyre, P. D. (2016). Foreign Language Enjoyment and Foreign Language Classroom Anxiety. The right and left feet of FL learning? In P. MacIntyre, T. Gregersen \& S. Mercer (Eds.), Positive psychology in SLA (pp. 215-236). Bristol: Multilingual Matters.

Dewaele, J.-M. \& MacIntyre, P.D. (2019). The predictive power of multicultural personality traits, learner and teacher variables on foreign language enjoyment and anxiety. In M. Sato \& S. Loewen (Eds.), Evidence-based second language pedagogy: A collection of Instructed Second Language Acquisition studies (pp. 263-286). London: Routledge.

Dewaele, J.-M., Witney, J., Saito, K., \& Dewaele, L. (2018). Foreign language enjoyment and anxiety in the FL classroom: the effect of teacher and learner variables. Language Teaching Research, 22(6), 676-697.

Dörnyei, Z., \& Csizér, K. (1998). Ten commandments for motivating language learners: Results of an empirical study. Language Teaching Research, 2, 203-229.

Dörnyei, Z., \& Murphy, T. (2003). Group dynamics in the language classroom. Cambridge: Cambridge University Press.

Dresel, M., \& Hall, N. C. (2013). Motivation. In N. C. Hall \& T. Goetz (Eds.), Emotion, motivation, and self-regulation: A handbook for teachers (pp. 57-122). Bingley, UK: Emerald Group Publishing.

Duckworth, A. L., \& Yeager, D. S. (2015). Measurement matters: Assessing personal qualities other than cognitive ability for educational purposes. Educational Researcher, 44, 237-251.

Erten, I. H. \& Erten, N. (2014). Academic self-concept and students 'achievement in the sixth grade Turkish course: A preliminary analysis. International Online Journal of Education and Teaching, 1(2), 46-55. 
Fredrickson, B.L. (2003). The value of positive emotions. American Scientist, 91 (4), 330-335.

Frenzel, A. C., \& Stephens, E. J. (2013). Emotions. In N. C. Hall \& T. Goetz (Eds.), Emotion, motivation, and self-regulation: A handbook for teachers (pp. 1-56) Bingley, UK: Emerald.

Gregersen, T., \& MacIntyre, P. (2014). Capitalizing on Individual Differences: From Premise to Practice. Bristol: Multilingual Matters.

Hazlett A. (2012). Higher-order epistemic attitudes and intellectual humility. Episteme 2012 $9(3), 205-223$.

Horwitz, E. (2017). On the misreading of Horwitz, Horwitz and Cope (1986) and the need to balance anxiety research and the experiences of anxious language learners. In Gkonou, C, Daubney, M., \& Dewaele, J.-M. (Eds.), New Insights into Language Anxiety: Theory, Research and Educational Implications (pp. 31-47). Bristol: Multilingual Matters.

Horwitz, E. K., Horwitz, M., \& Cope, J. (1986). Foreign language classroom anxiety. Modern Language Journal, 70, 125-132.

Hoyle, R., Davisson, E., Diebels, K. \& Leary, M. (2016). Holding specific views with humility: Conceptualization and measurement of specific intellectual humility. Personality and Individual Differences, 97, 165-172.

Krumrei-Mancuso, E. J. (2017). Intellectual humility and prosocial values: Direct and mediated effects. The Journal of Positive Psychology, 12(1), 13-28.

Krumrei-Mancuso, E. J. (2018). Intellectual humility's links to religion and spirituality and the role of authoritarianism. Personality and Individual Differences, 130, 65-75.

Krumrei-Mancuso, E. J., \& Rouse, S. V. (2016). The development and validation of the comprehensive intellectual humility scale. Journal of Personality Assessment, 98(2), 209221.

Krumrei-Mancuso, E. J., Haggard, M. C., Labouff, J. P., \& Rowatt, W. C. (2020). Links between intellectual humility and acquiring knowledge. The Journal of Positive Psychology, $15,155-170$.

Leary, M. R., Diebels, K. J., Davisson, E. K., Jongman-Sereno, K. P., Isherwood, J. C., Raimi, K. T., \& Hoyle, R. H. (2017). Cognitive and interpersonal features of intellectual humility. Personality and Social Psychology Bulletin, 43(6), 793-813.

Leary, M.R. (2016). Holding specific views with humility: Conceptualization and measurement of specific intellectual humility. Personality and Individual Differences, 97, 165-172.

MacIntyre, P. D. \& Gregersen, T. (2012) Emotions that facilitate language learning: The positive-broadening power of the imagination. Studies in Second Language Learning and Teaching 2 (2), 193-213.

Moskowitz, S., \& Dewaele, J.-M. (2019). Is teacher happiness contagious? A study of the link between perceptions of language teacher happiness and student attitudes. Innovation in Language Learning and Teaching, 1-14. doi: 10.1080/17501229.2019.1707205

Plonsky, L., \& Ghanbar, H. (2018). Multiple regression in L2 research: A methodological synthesis and guide to interpreting $\mathrm{R}^{2}$ values. The Modern Language Journal, 102(4), 713 731.

Porter, T., \& Schumann, K. (2018). Intellectual humility and openness to the opposing view. Self and Identity, 17(2), 139-162.

Pritchard, D. (2018). Intellectual humility and the epistemology of disagreement. Synthese. An International Journal for Epistemology, Methodology and Philosophy of Science. doi: 10.1007/s11229-018-02024-5

Roberts, R. C., \& Wood, W. J. (2003). Humility and epistemic goods. In M. DePaul \& L. Zagzebski (Eds.), Intellectual virtue: Perspectives from ethics and epistemology (pp. 257279). New York, NY: Oxford University Press. 
Samuelson, P.L., Church, I.M., Jarvinen, M., \& Paulus, T. (2015). The science of intellectual humility white paper. Retrieved from http://thethrivecenter.org/wpcontent/uploads/2015/08/IH-White-Paper.pdf

Vorobej, M. (2011). Distant peers. Metaphilosophy, 42, 708-722.

Zmigrod, L., Zmigrod, S., Rentfrow, P. \& Robbins, T. (2019). The psychological roots of intellectual humility: The role of intelligence and cognitive flexibility. Personality and Individual Differences, 141, 200-208.

\section{Copyrights}

Copyright for this article is retained by the author(s), with first publication rights granted to the Journal.

This is an open-access article distributed under the terms and conditions of the Creative Commons Attribution license (CC BY-NC-ND) (http://creativecommons.org/licenses/by-nc-nd/4.0/). 